\title{
Infecção do trato urinário em pacientes ambulatoriais: prevalência e perfil de sensibilidade frente aos antimicrobianos no período de 2009 a 2012
}

Ilo Odilon Villa Dias ${ }^{1}$, Alessandra de Mello Coelho², Ionara Dorigon²

\begin{abstract}
RESUMO
As Infecções do Trato Urinário (ITU) são demandas frequentes na clínica médica ocorrendo em todas as idades, as quais acometem principalmente mulheres. O objetivo deste estudo foi identificar os microorganismos prevalentes nas ITU dos pacientes atendidos em um Laboratório comunitário na cidade de Chapecó-SC, juntamente com o perfil de sensibilidade frente aos antimicrobianos, assim como a faixa etária e o gênero dos pacientes em que mais ocorreram as infecções. Foi realizado um estudo retrospectivo epidemiológico através da analise dos laudos no período de três anos (setembro de 2009 a setembro de 2012). No período em que se compreendeu este estudo, 550 amostras foram positivas, sendo que $82,4 \%$ eram pacientes mulheres com faixa etária entre 26 a 38 anos. 0 agente etiológico mais frequente foi a Escherichia coli e, entre os antimicrobianos testados, as fluorquinolonas foram a classe que mais apresentou resistência, com $40,1 \%$, e a nitrofurantoína a de menor índice de resistência, com 1,6\%. Estes resultados coincidem com outros de diferentes regiões, entretanto, mais estudos são necessários com amostragem maior e em diferentes momentos.
\end{abstract}

Descritores: Infecção do Trato Urinário; Antibióticoterapia; Resistência Bacteriana.

\section{Urinary tract infection in outpatients: prevalence and antimicrobial susceptibility profile in a study conducted from 2009 to 2012}

\begin{abstract}
Urinary Tract Infections (UTI) are a common and frequent complaint in clinical medicine, which occur at any age mainly in women. This study aimed to identify the prevalent microorganisms in UTI in patients served in a communitarian Lab in the city of Chapecó-SC, along with the susceptibility profile against antimicrobials as well as the age and gender group with the highest occurrence of infections. A retrospective epidemiologic study was carried on through the analysis of appraisal reports over three years (September 2009 to September 2012). Over the period this study was conducted, 550 samples were positive, from those, $82.4 \%$ belonged to women, and the age group with most prevalence was that from 26 to 38 years old. The most frequent etiologic agent was Escherichia coli; among the tested antimicrobial the class of fluoroquinolones presented the highest resistance with $40.1 \%$ and the class of nitrofurantoin presented the lowest resistance rate with $1.6 \%$. These results match with others from different regions, nevertheless, further studies are necessary with larger sample size as well as in different moments.
\end{abstract}

Descriptors: Urinary Tract Infection, Antibiotic Therapy; Bacterial Resistance.

${ }^{1}$ Professor titular do Curso de Graduação em Farmácia e dos Cursos de Pós-Graduação em Análises Clínicas e Farmacologia Clínica na Universidade Comunitária da Região de Chapecó (UNOCHAPECÓ), Chapecó, SC, Brasil.

${ }^{2}$ Farmacêutica pela Universidade Comunitária da Região de Chapecó (UNOCHAPECÓ), Chapecó, SC, Brasil. 


\section{Introdução}

A Infecção do Trato Urinário (ITU) pode ser definida como a invasão e multiplicação bacteriana nos tecidos do trato urinário, desde a uretra podendo chegar até os rins, principalmente através da via ascendente, mas também hematogênica e linfática, sendo uma das infecções bacterianas mais comuns e uma das principais razões para a prescrição de antimicrobianos e, considerada a segunda infecção mais comum em seres humanos ${ }^{1}$. O seu maior risco é causar pielonefrite e, nos casos de graves complicações evoluir a uma septicemia e a morte ${ }^{2}$. As ITU ocorrem em todas as idades, havendo, contudo, maior prevalência em crianças até os 6 anos, mulheres jovens com vida sexual ativa, e idosos com mais de 60 anos $^{3}$, nestes, sendo a causa mais comum de bacteremia e responsáveis por altas taxas de morbimortalidade 4 .

A condição mais comum na predisposição à ITU é o fluxo urinário comprometido mecânica ou funcionalmente ${ }^{5}$, mal formações congênitas ${ }^{6}$, alterações hormonais favorecendo a colonização vaginal por bactérias nefrogênicas ${ }^{7}$, e a extensão curta e localização anatômica da uretra na mulher ${ }^{6}$. Já a uretra longa e os fluidos prostáticos bactericidas dificultam a infecção em homens ${ }^{8} \mathrm{e}$, ainda a utilização de antimicrobianos específicos ${ }^{9} \mathrm{e}$ a prevenção com vacinas são profiláticos ${ }^{10}$.

Entre os sintomas clássicos de ITU estão a disúria, polaciúria, urgência miccional, dor lombar, alterações de cor e odor urinário e, em aproximadamente $30 \%$ dos casos com sangue visível na urina². Em lactentes, o quadro tende a ser inespecífico, e a febre, muitas vezes, é o único sinal ${ }^{11}$. Nos casos de pielonefrite, os sinais e sintomas clínicos incluem dor no flanco (uni ou bilateral) ou abdominal, febre, mal-estar geral, anorexia, náuseas e vômitos, frequentemente associados a graus variáveis de desidratação, calafrios, cefaléia e taquipnéia ${ }^{12}$.

As bactérias gram-negativas são as principais responsáveis pelas ITU, sendo a Escherichia coli a mais comum, isolada em cerca de $70 \%$ a $90 \%$ dos casos, seguido do Staphylococcus saprophyticus, responsáveis por taxas entre 10\% a $20 \%$ em mulheres jovens, sexualmente ativas, sendo a segunda causa mais comum nestas ${ }^{13}$.

Testes rápidos como do nitrito e o da esterase de leucócitos associado à análise microscópica do sedimento urinário, a observação pelo Gram, são úteis, mas não superam a urocultura, considerada como padrão-ouro para o diagnóstico laboratorial das ITU. Já o hemograma e as dosagens de uréia e creatinina séricas, servem para indicar a agressividade da infecção e considera-se a ecografia de rins e vias urinárias um exame complementar importante ${ }^{12}$.

O tratamento adequado das ITU de origem bacteriana requer o conhecimento do perfil bacteriológico atualizado e de resistência frente aos antimicrobianos utilizados. Este deve ser específico para cada tipo de microrganismo infectante, sendo assim, a escolha do antimicrobiano mais adequado é baseada no Teste de Sensibilidade aos Antimicrobianos (TSA), que determina a resposta das bactérias aos antibióticos estudados ${ }^{14}$, e deve ser a base para a antibióticoterapia dirigida e adequada ${ }^{15}$.

Os esquemas terapêuticos levam em consideração a eficácia do medicamento e a excreção urinária das drogas utilizadas, além de toxicidade, custo e comodidade posológica para os pacientes, disponíveis em diversos antibióticos utilizados ${ }^{16}$. Porém, a demora no diagnóstico das infecções ${ }^{17}$ a utilização indiscriminada, empírica ou errônea de antibióticos no tratamento é discutida atualmente como sendo responsável pelo desenvolvimento de resistência bacteriana a estes ${ }^{15}$, tornando-se uma preocupação mundial, principalmente nos países em desenvolvimento ${ }^{18}$. Esse aumento da resistência tem sido relatado nos últimos anos e sua constante mudança deve ser levada em consideração na escolha da estratégia para o tratamento com antimicrobiano ${ }^{19}$.

A resistência pode ser considerada um fenômeno ecológico que ocorre como resposta da bactéria frente ao amplo uso de antibióticos e sua presença no meio ambiente ${ }^{17}$. A emergência e disseminação de inúmeros microorganismos resistentes resultam da combinação de múltiplos fatores, tais como: mutações dos genes de resistência que aumentam seu espectro de atividade; troca de informações genéticas nas quais os genes de resistência são transferidos para novos microrganismos; pressão seletiva exercida pelas condições do meio que favorece a emergência e disseminação de microrganismos resistentes; proliferação e disseminação de clones multirresistentes as quais podem ocorrer em nível global ${ }^{20}$.

Estudos demonstram que o nível de resistência microbiana vem aumentando, não só em pacientes hospitalizados, mas também em pacientes ambulatoriais. Com isso, faz-se necessário que mais pesquisas sejam desenvolvidas fora do ambiente hospitalar, para que novas formas de tratamento possam ser desenvolvidas a fim de tratar efetivamente infecções por bactérias com sensibilidade diminuída aos tratamentos convencionais ${ }^{13,21}$. Há relatos que indicam claramente que a resistência aos antibióticos contra a $E$. coli causadoras de ITU comunitária vem obtendo um crescimento significativo ${ }^{18,22}$. Portanto, monitorar o comportamento frente aos antimicrobianos e conhecer o padrão de resistência dos microrganismos causadores de ITU, a fim de que o tratamento, mesmo que empírico, possa resultar na sua eliminação, é muito importante ${ }^{14}$. 
Assim, o objetivo do presente estudo foi identificar os microorganismos prevalentes, bem como seu perfil de sensibilidade frente aos antimicrobianos, relacionando-os com a faixa etária dos pacientes que procuraram atendimento em um Laboratório privado não hospitalar, de atendimento comunitário na cidade de Chapecó, Santa Catarina, no período compreendido entre setembro de 2009 a setembro de 2012.

\section{Metodologia}

Realizou-se um estudo retrospectivo quantitativo com levantamento epidemiológico dos dados, onde se analisaram todos os laudos de ITU dos pacientes que buscaram atendimento em um Laboratório privado não hospitalar, de atendimento comunitário na cidade de Chapecó, região oeste de Santa Catarina, no período de setembro de 2009 a setembro de 2012.

Os pacientes foram orientados a coletar a urina de jato médio, após higienização da genitália, em frasco estéril, fornecido pelo laboratório e logo após as amostras foram processadas. As uroculturas foram realizadas de forma quantitativa, semeandose, com alça calibrada, em volumes de 0,01 $\mathrm{ml}(10 \mu \mathrm{l})$ de urina em ágar MacConkey, que permite 0 crescimento seletivo de bacilos gram-negativos diversos e em ágar Cystine Lactose Electrolyte Deficient (CLED), que permite o crescimento de todos os microrganismos potencialmente patogênicos presentes na urina. Foram consideradas positivas as uroculturas com contagem de colônias $\geq 105$ unidades formadoras de colônia (UFC)/ml de urina, após incubação em estufa bacteriológica entre $35^{\circ} \pm 2^{\circ} \mathrm{C}$ durante 24 a $48 \mathrm{~h}^{24}$. O TSA foi realizado através da metodologia de disco-difusão, segundo o Clinical and Laboratory Standards Institute-200825. Foram excluídos do estudo os laudos de exames negativos, os não concluídos e os em duplicata, onde foram isolados o mesmo microrganismo do mesmo paciente.

Os antibióticos testados na classe dos beta-lactâmicos, foram ceftazidima, penicilina G, cefalexina, amoxicilina+clavulanato de potássio, cefalotina, ceftriaxona, cefoxitina, cefepime, oxacilina, cefotaxima, tazobactan/piperacilina. Em homens, além destes foram testados também ampicilina e aztreonam. As fluorquinolonas testadas foram ácido nalidíxico, ácido pipemídico, norfloxacino e ciprofloxacino. A sulfonamida testada foi o sulfametoxazol+trimetroprim. 0 glicopeptídeo testado foi a vancomicina. Os aminoglicosídeos testados foram gentamicina e amicacina. O macrolídeo testado somente para homens com infecção por Staphylococcus coagulase negativa, foi a eritromicina. Depois de testados frente à bactéria isolada, esta foi considerada resistente sempre que não era sensível a pelo menos um antibiótico avaliado no TSA.

Os dados coletados foram organizados, e a frequência dos principais patógenos foi determinada. Os dados referentes à sensibilidade aos antimicrobianos foram analisados e reunidos de acordo com o percentual de resistência a cada um dos testados.

Este estudo foi aprovado pelo Comitê de Ética em Pesquisa (CEP) em seres humanos da UNOCHAPECÓ, sob o número 310/12.

\section{Resultados e discussão}

No período em que compreendeu este estudo 550 amostras foram positivas, indicando ITU. Destas amostras, 82,4\% ( $n=453)$ pertenciam à pacientes do gênero feminino e 17,6\% ( $n=97)$ ao masculino (Figura 1), o que é corroborado pela literatura, que indica a prevalência de ITU em pacientes do gênero feminino. Rodrigues e Barroso ${ }^{14}$, na cidade da Guarda em Portugal no ano de 2011 em um estudo de 200 laudos de pacientes com ITU encontraram 84\% dos casos no gênero feminino. Em trabalhos realizados por Lo et. al., ${ }^{26}$ Santana et. al., ${ }^{3}$ Martini et. al. ${ }^{23}$ e Hoyos et. al., ${ }^{27}$ apontaram a prevalência de 72,6\%, 69\%, 73\% e $55,6 \%$ respectivamente no gênero feminino. Já Hörner et. al., ${ }^{28}$ identificou em amostras hospitalares que $77,9 \%$ eram mulheres e 22,1\% homens e em amostras comunitárias, $89,8 \%$ eram mulheres, 4,3\% eram homens além de 5,8\% crianças.

As ITU podem ocorrer em qualquer fase da vida ${ }^{23}$, porém, as faixas etárias mais afetadas identificadas neste estudo (Tabela 1), entre mulheres foi a de 26 a 38 anos, concentrando $27,8 \%$ ( $n=126)$ dos casos, entretanto, devemos considerar o número de casos na faixa etária de 13 a 51 anos, com 60,8\% ( $n=276)$, condizente com a fisiologia hormonal feminina. Martini et. al., ${ }^{23}$ relata que essa faixa etária corresponde à fase fértil da mulher, a qual normalmente se encontra em atividade sexual, e mais propícia às ITU.

Já, nosso estudo demonstrou que entre os homens, 28,8\% ( $n=28)$ dos casos ocorreram entre 0 e 12 anos, concordando com a prevalência descrita na literatura ${ }^{3,6,27}$. Chama atenção a diminuição significativa de casos de ITU em mulheres a partir dos 52 anos, entretanto, em homens se observa o contrário, ou seja, um aumento de casos a partir dessa idade. 
Esse perfil permanece até a idade de 90 anos em ambos os gêneros, e a partir dos 91 anos há uma queda da incidência de casos de ITU, provavelmente pela diminuição da população com essa idade ou pelas características comunitárias da amostra analisada (Tabela 1). Estes achados são semelhantes aos de Rodrigues e Barroso ${ }^{14}$. Na pesquisa de Santana et. al., ${ }^{3}$ a faixa etária mais afetada foi acima de 60 anos, coincidindo com a de Molano et. al. ${ }^{29}$ que encontrou uma media de idade de 62,5 anos como a prevalente. Hoyos et. al. ${ }^{27}$ identificou a faixa etária de 1 a 12 meses como a mais atingida, em ambos os gêneros. Martini et. al. ${ }^{23}$ identificou $37,6 \%$ dos casos entre mulheres de 14 a 40 anos, o que corrobora para os achados em nossa pesquisa em Chapecó. Entretanto, entre os homens o estudo torna-se divergente, já que a faixa etária com maior incidência foi entre 41 e 64 anos com 10,6\%.

Figura 1 - Distribuição dos casos de ITU de acordo com gênero, espécie prevalente e resistência.

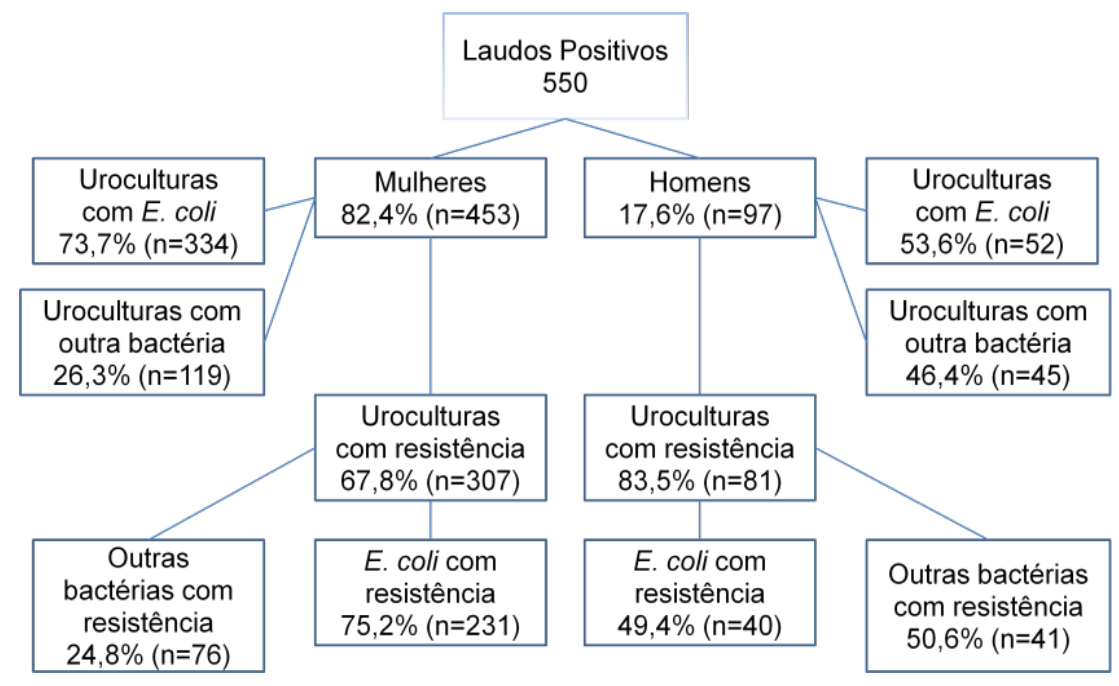

Tabela 1 - Distribuição dos casos de ITU por gênero de acordo com a faixa etária.

\begin{tabular}{c|c|c|c|c}
\hline \multirow{2}{*}{ Idade em anos } & \multicolumn{2}{|c|}{ Homens } & \multicolumn{2}{c}{ Mulheres } \\
\cline { 2 - 5 } & $\mathbf{n}$ & $\%$ & $\mathbf{n}$ & $\%$ \\
\hline 0 a 12 & 28 & 28,8 & 97 & 21,4 \\
\hline 13 a 25 & 05 & 5,1 & 95 & 20,9 \\
\hline 26 а 38 & 05 & 5,1 & 126 & 27,8 \\
\hline 39 a 51 & 14 & 14,4 & 55 & 12,1 \\
\hline 52 a 64 & 15 & 15,4 & 30 & 6,6 \\
\hline 65 a 77 & 17 & 17,5 & 30 & 6,6 \\
\hline 78 a 90 & 12 & 12,3 & 15 & 3,3 \\
\hline 91 a 104 & 01 & 1,0 & 05 & 1,1 \\
\hline
\end{tabular}

A E. coli extraintestinal, "Uropathogenic E.coll" (UPEC) causa frequentemente ITU, devido ao fato de possuir fatores de virulência como as fímbrias do tipo 1 e $P$, que se aderem nas células da uretra e iniciam a infecção ${ }^{23}$. Confirmando essa patogenicidade, a bactéria prevalente neste estudo foi a $E$. coli (Figura 1), tanto em amostras de pacientes do gênero feminino $73,7 \%$ ( $n=334$ ) quanto nas dos pacientes do gênero masculino 53,6\% ( $n=52)$, condizente com os achados por Rodrigues e Barroso ${ }^{14}$, com 65\%, Lo et. al.. ${ }^{26} 76,6 \%$, Machado-Alba e Murillo-Muñoz, ${ }^{30} 67,2 \%$, Santana et. al., ${ }^{3} 44,4 \%$, e Hoyos et. al., ${ }^{27} 74 \%$. O estudo de Hörner et. al. ${ }^{28}$ encontrou nas amostras comunitárias $60 \%$ de E. coli e nas amostras nosocomiais $47,2 \%$. Também observamos a resistência específica dos uropatógenos por faixa etária em mulheres (Figura 2) e em homens (Figura 3). 
Figura 2 - Resistência bacteriana em mulheres por microrganismos/espécies bacterianas e faixa etária.

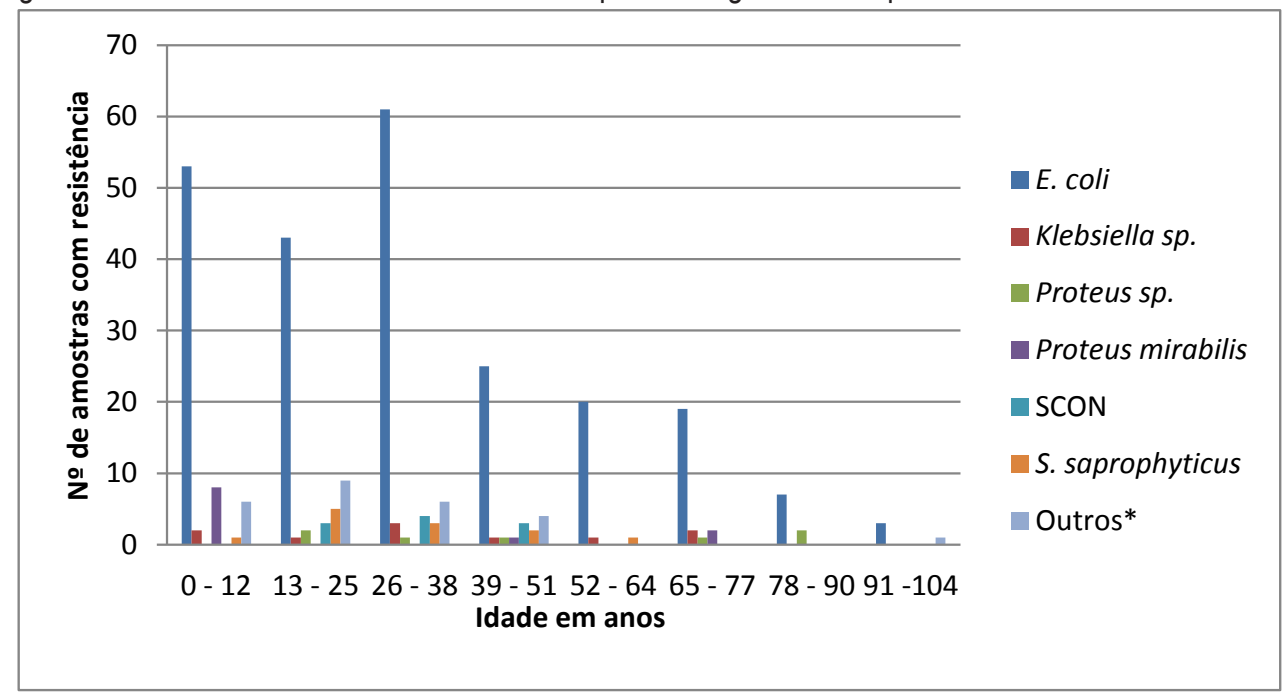

E. coli $=$ Eschericia coli; SCON = Staphylococcus Coagulase Negativo; $S$. saprophyticcus = Staphylococcus saprophyticcus

* Enterobacter sp., Citrobacter sp., Morganella morganii, Pseudomonas sp., Enterobacter aerogenes, Klebsiella ozenae, Proteus vulgaris, Enterobacter agglomerans, Klebsiella pneumoniae, Serratia sp., S. aureus, Streptococcus sp.

Figura 3 - Resistência bacteriana em homens por microrganismos/espécies bacterianas e faixa etária.

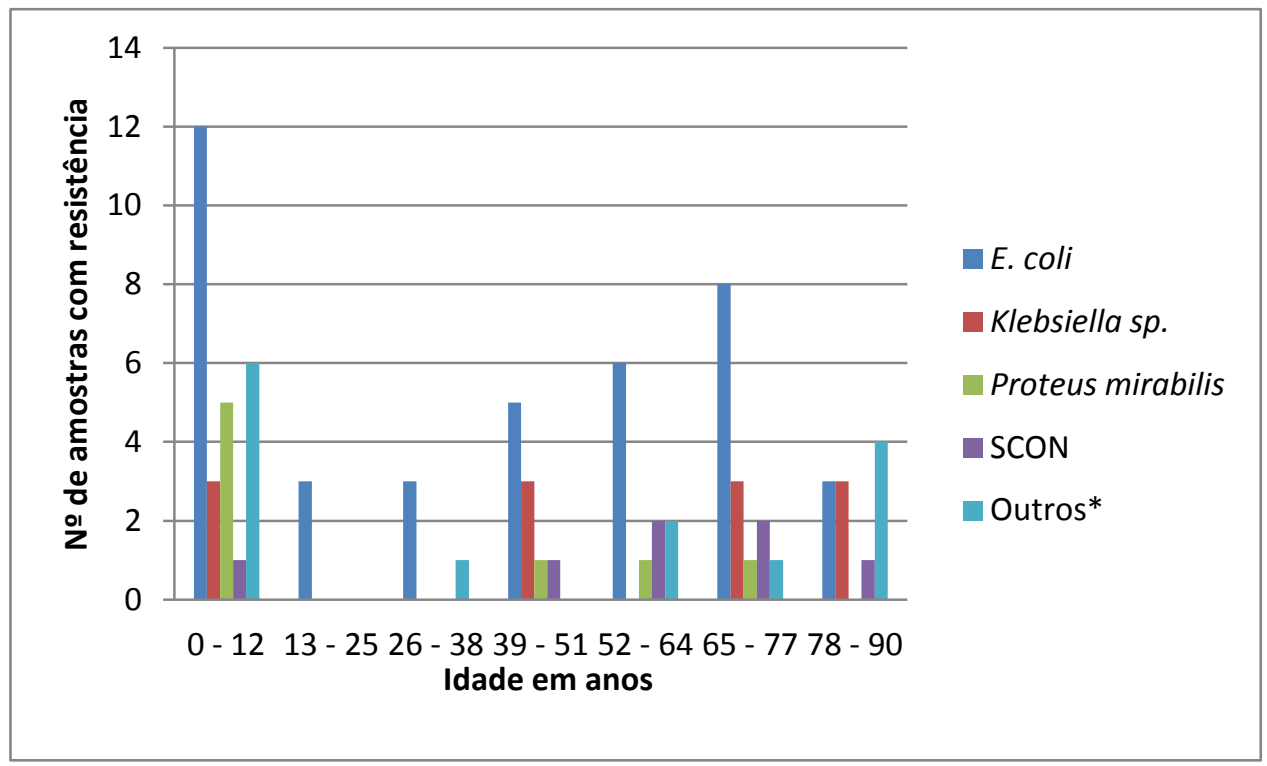

E. coli = Eschericia coli; $\mathrm{SCON}=$ Staphylococcus Coagulase Negativo

* Streptococcus sp., Klebsiella oxytoca, Enterobacter agglomerans, Serratia sp., Citrobacter sp., Proteus vulgaris, P. rettgeri, Pseudomonas sp., Pseudomonas aeruginosa, Proteus sp.

Quando observamos a resistência, esta apresentou-se principalmente nas uroculturas de mulheres, $(67,8 \% / \mathrm{n}=307)$, sendo a $E$. coli a bactéria prevalente $(75,2 \% / n=231)$. Nas uroculturas dos pacientes do gênero masculino, essa resistência foi de $83,5 \%(n=81)$, sendo a $E$. coli responsável pelas maiores taxas de isolamento, 49,4\% $(n=40)$ (Figura 1). Essa resistência percebida foi individualizada por bactéria e os antibióticos distribuídos em classes, como dispostos na Tabela 2. 
Tabela 2 - Distribuição dos casos de resistência de acordo com gênero, microrganismo e classe de antibióticos.

\begin{tabular}{c|c|c|c|c|c|c|c}
\multicolumn{7}{c}{ Mulheres - Resistência bacteriana por classe de antibióticos em \% } \\
\hline Microrganismo & $\beta$-lac & Fluorq & Tetrac & Nitrof & Sulfon & Aminog & \\
\hline E. coli & 23,5 & 37,4 & 17,8 & 1,2 & 16,9 & 3,1 & \\
\hline Klebsiella sp. & 38,6 & 41,4 & 7,1 & 2,9 & 8,6 & 1,4 & \\
\hline Proteus sp. & 50 & NT & 25 & 12,5 & 12,5 & NT & \\
\hline P. mirabilis & 15,9 & 29,5 & 25 & 13,6 & 13,6 & 2,3 & \\
\hline SCON & 34,5 & 24,1 & 17,2 & 3,4 & 17,2 & 3,4 & \\
\hline S. saprophyticus & 31,2 & 6,2 & 37,5 & NT & 25 & NT & \\
\hline Outros* & 56,2 & 10,5 & 12,4 & 8,6 & 10,5 & 1,9 & \\
\hline
\end{tabular}

Homens - Resistência bacteriana por classe de antibióticos em \%

\begin{tabular}{c|c|c|c|c|c|c|c}
\hline Microrganismo & $\beta$-lac & Fluorq & Tetrac & Nitrof & Sulfon & Aminog & Macrol \\
\hline E. coli & 22,7 & 42,8 & 15,3 & 2,1 & 13,7 & 3,2 & NT \\
\hline Klebsiella sp. & 30,5 & 38,9 & 9,7 & 9,7 & 8,3 & 2,8 & NT \\
\hline P. mirabilis & 30,8 & 30,8 & 15,4 & 10,2 & 10,2 & 2,6 & NT \\
\hline SCON & 38,9 & 33,3 & 5,6 & NT & 5,6 & 11,1 & 5,6 \\
\hline Outros $^{*}$ & 36,6 & 26,6 & 12,2 & 8,9 & 14,4 & 1,1 & NT \\
\hline
\end{tabular}

E. coli = Eschericia coli; $S$. saprophyticcus = Staphylococcus saprophyticcus; $P$. mirabilis = Proteus mirabilis

$\beta$-lac: $\beta$-lactâmicos; Fluorq: Fluorquinolonas; Tetrac: Tetraciclina; Nitrof: Nitrofurantoína; Sulfon: Sulfonamidas; Aminog: Aminoglicosídeos; Macrol: Macrolídeos.

SCON = Staphylococcus Coagulase Negativo.

NT = Não Testado.

${ }^{*}$ Enterobacter sp., Citrobacter sp., Morganella morganii, Pseudomonas sp., Enterobacter aerogenes, Klebsiella ozenae, Proteus vulgaris, Enterobacter agglomerans, Klebsiella pneumoniae, Serratia sp., S. aureus, Streptococcus sp., Klebsiella oxytoca, P. rettgeri, Pseudomonas aeruginosa, Proteus sp.

Entre as mulheres que apresentavam ITU causadas por Klebsiella sp., Proteus sp., P. mirabilis, Staphylococcus coagulase negativo e Staphyloccocus saprophyticus, a resistência foi de 3,3\%, 2,3\%, 3,6\%, 3,3\% e 3,9\%, respectivamente. E, para os demais microrganismos isolados nas ITU femininas (Enterobacter sp., Citrobacter sp., Morganella morganii, Pseudomonas sp., Enterobacter aerogenes, Klebsiella ozenae, Proteus vulgaris, Enterobacter agglomerans, Klebsiella pneumoniae, Serratia sp., S. aureus, Streptococcus sp.) e identificados nas uroculturas, a resistência foi de 8,5\%.

Nas ITU masculinas causadas por Klebsiella sp., P. mirabilis, Staphylococcus coagulase negativo a resistência foi de $14,8 \%, 9,9 \%$ e 8,6\% respectivamente. Para outros microrganismos encontradas nas ITU (Streptococcus sp., Klebsiella oxytoca, Enterobacter agglomerans, Serratia sp., Citrobacter sp., Proteus vulgaris, P. rettgeri, Pseudomonas sp., Pseudomonas aeruginosa, Proteus sp.) em homens, identificados nas uroculturas, a resistência foi de 17,3\%. Já para Proteus sp., não houve resistência de acordo com os laudos analisados neste estudo.

Podemos observar que o perfil de resistência para os mesmos microrganismos é diferente entre os gêneros, onde no masculino é em média 3,3 vezes maior que no feminino, exceto a diferença de resistência da $E$. coli que é de 1,2. Entretanto, dentro do mesmo gênero, considerando os microorganismos causadores de ITU, a resistência é semelhante entre estes, com exceção da $E$. coli que se destaca na resistência, tanto no gênero feminino quanto no masculino. Resultado semelhante foi encontrado em Carmo et. al. ${ }^{22}$

É importante destacar que este trabalho avaliou casos de ITU comunitárias, onde o conjunto de fatores que contribuem para a morbidade são menores do que das hospitalares; e que o tipo de prescrição é particularizado regionalmente, uma vez que os profissionais prescritores são de diferentes escolas de medicina. Outro fator importante é o acesso da população aos antimicrobianos, que perpassa pela questão econômica e políticas públicas que disponibilizem o medicamento, além da devida orientação quanto ao uso racional destes, considerando que estes fatores somados aos intrínsecos as bactérias, tem implicações no desenvolvimento de resistência.

Estudo realizado por Rodrigues e Barroso ${ }^{14}$, comparando o comportamento da E. coli, K. pneumoniae e P. aeruginosa, nos anos de 2002 e 2007, observou uma diminuição de sensibilidade frente a antimicrobianos gentamicina, trimetroprim, ceftazidima, nitrofurantoina, imipenem e cefotaxima. Já, Lo et. al. ${ }^{26}$ analisando o perfil de sensibilidade frente aos 
antimicrobianos para E.coli, no qual foi observado sensibilidade igual ou inferior a 70\% para ampicilina, sulfametoxazoltrimetoprim e cefalotina e acima de $90 \%$ para cefalosporinas de segunda e terceira geração, aminoglicosídeos, quinolonas, nitrofurantoína e ácido nalidíxico e de $83,4 \%$ para amoxicilina-clavulanato. No estudo de Machado-Alba e Murillo-Muñoz ${ }^{30}$, o perfil de resistência da $E$. coli foi de $54,7 \%$ para ampicilina, $50 \%$ para amoxicilina, $43,8 \%$ para sulfametoxazol associado a trimetroprim e $45,8 \%$ para cefalotina. Entretanto, o mesmo microrganismo apresentou $100 \%$ de sensibilidade para amoxicilina-clavulanato, 94,8\% para nitrofurantoína, 86,3\% para ceftriaxona, e $71 \%$ para ciprofloxacino. Já a Klebsiella sp. apresentou sensibilidade de $83,3 \%$ a $100 \%$ para norfloxacina, ciprofloxacina, nitrofurantoina, gentamicina, ceftazidima e ceftriaxona e o perfil de resistência foi de $86,7 \%$ para piperacilina-tazobactam, $66,7 \%$ para ampicilina, $60 \%$ para amoxicilina e $50 \%$ para amoxicilina-clavulanato. Em estudo de Hoyos et. al. ${ }^{27}$ o perfil de resistência da $E$. coli, considerando os maiores índices, foi de $85,7 \%$ para cefalotina, $76,6 \%$ para ampicilina, $53,8 \%$ para sulfametoxazol-trimetroprim, $50 \%$ para ampicilina associada ao sulbactam e o menor índice/taxa foi de $5 \%$ para nitrofurantoína. Já o P. mirabilis apresentou $100 \%$ de resistência para nitrofurantoína, 28,5\% para ampicilina, 25\% para sulfametoxazol-trimetroprim e 14,2\% para ampicilina com sulbactam. A K. pneumoniae apresentou 100\% de resistência para cefalotina, ampicilina, amoxicilina-clavulanato, cefuroxima e ceftazidima, $86 \%$ para nitrofurantoína, $80 \%$ para ampicilina com sulbactam, $66 \%$ para cefepima, 50\% para ceftriaxona e aztreonam e $40 \%$ para piperacilina e tazobactam.

No Brasil, o acesso aos antimicrobianos era bastante facilitado com sua venda livre, o que pode ter contribuído para o aumento da resistência bacteriana ao longo dos anos, entretanto, a partir da ação de agencia reguladora governamental (RDC/44/ANVISA, de 26 de outubro de $2010^{31}$ ), que obriga a dispensação de antimicrobianos mediante prescrição médica, bem como a retenção e registro desta pela farmácia dispensadora, racionalizou de maneira significativa 0 uso destes pela população. Porém, somente ao longo do tempo, com pesquisas de monitoramento, é que poderá se observar o resultado dessa medida. Considerando que a maioria do seu uso ocorre na comunidade, os estudos de base populacional são instrumentos preciosos para um melhor conhecimento das realidades locais ${ }^{32}$. Por isso, a importância de se realizarem estudos com o objetivo de conhecer os principais agentes causadores de ITU e o perfil de resistência e sua evolução ao longo dos anos ${ }^{13}$, uma vez que não é recomendada a utilização de um determinado fármaco na terapia empírica quando a sua taxa de resistência local for superior a $20 \%{ }^{19}$ Braios et. al. ${ }^{13}$ indica a necessidade da repetição de trabalhos ao longo do tempo, pois poderão demonstrar possíveis modificações, tanto na prevalência quanto no padrão de resistência e, assim, fornecer subsídios para reorientar a terapêutica antimicrobiana regional. 0 estudo do predomínio da microbiota patogênica e o monitoramento do perfil de susceptibilidade em uma determinada região podem auxiliar clínicos e farmacêuticos, no acompanhamento terapêutico e na orientação dos pacientes ${ }^{19}$.

Portanto, trabalhos como este, garantirão ao longo do tempo, a segurança na utilização de antimicrobianos frente a casos de ITU, e trarão importante contribuição para o desenvolvimento de ações de planejamento e intervenção na saúde regional.

\section{Considerações Finais}

Dos laudos analisados para o desenvolvimento desse estudo, $82,4 \%$ pertenciam a mulheres e $17,6 \%$ a homens, apontando o gênero feminino como o mais prevalente em ITU. A faixa etária prevalente foi de 26 a 38 anos entre as mulheres, representando $27,8 \%$ dos casos, e de 0 e 12 anos entre os homens, com 28,8\% dos casos. 0 agente etiológico mais frequente foi a $E$. coli, presente em $73,7 \%$ das ITU femininas e $53,6 \%$ das masculinas, sendo também o que mais apresentou resistência; $75,2 \%$ em mulheres e 49,4\% em homens. Dos antimicrobianos testados para 0 agente mais frequente, as fluorquinolonas foram à classe que mais apresentou resistência, com 37,4\% em mulheres e 42,8\% em homens. A nitrofurantoína foi o antimicrobiano com menor índice de resistência, com 1,6\% na média para ambos os gêneros. Estes resultados coincidem com os achados em diferentes locais, descritos na literatura, entretanto, tratouse de uma pesquisa focada em apenas uma parcela da população. Portanto, serão necessários estudos posteriores com uma amostra ampliada, que transcenda a área de abrangência ora pesquisada e em diferentes momentos, para acompanhar as possíveis alterações nas variáveis pesquisadas. Esse acompanhamento poderá servir de referencia para metodologias de abordagem com antimicrobianos frente a casos de ITU. 
Agradecimentos

Ao Farmacêutico-Bioquímico Carlos Alberto Merísio, Laboratório Merisio de Análises Clínicas. Chapecó / SC.

Conflito de interesse

Não houve nenhum tipo de conflito de interesse no desenvolvimento deste estudo.

\section{Referências Bibliográficas}

1. Barberino MGMA. Prevalência de Resistência a Antimicrobianos e Uso de Testes Rápidos no Diagnóstico das Infecções do Trato Urinário Adquiridas na Comunidade. 2010. 100 p. Tese de Mestre em Biotecnologia em Saúde e Medicina Investigativa. Fundação Oswaldo Cruz - Centro de Pesquisa Gonçalo Moniz. Salvador-BA.

2. Moura LB, Fernandes MG. A Incidência de Infecções Urinárias Causadas por E. Coli. Rev. Olhar Cient., 1(2): 411-426, 2010. 3. Santana TCFS, Pereira EMM, Monteiro SG, Carmo MS, Turri RJG, Figueiredo PMS. Prevalência e resistência bacteriana aos agentes antimicrobianos de primeira escolha nas infecções do trato urinário no município de São LuísMA. Rev. Patol. Trop., 41(4): 409-418, 2012.

4. Dallacorte RR, Schneider RH, Benjamin WW. Perfil das infecções do trato urinário em idosos hospitalizados na Unidade de Geriatria do Hospital São Lucas da PUCRS. Scientia Medica. 17(4): 197-204, 2007.

5. Maldaner NIP, Cavalli V; Rossi EM, Scapin D, Sardigla CU. Antimicrobiano de Cepas de Escherichia coli Isolados de Pessoas com Suspeita de Infecção do Trato Urinário. RBAC., 43(2): 145-147, 2011.

6. Muller EV, Santos DF, Corrêa NAB. Prevalência de microrganismos em infecções do trato urinário de pacientes atendidos no laboratório de análises clínicas da Universidade Paranaense - Umuarama - PR. RBAC, 40(1): 35-37, 2008.

7. Grossman E, Caroni MM. Infecção urinária na adolescência. Adolesc. Saud., 6(4): 41-47, 2009.

8. Soares LA, Nishi CYM, Wagner HL. Isolamento das bactérias causadoras de infecções urinárias e seu perfil de resistência aos antimicrobianos. Rev. Bras. Med. Fam. Com. 2(6): 84-92, 2006.

9. Tavares W, Lopes HV, Castro R, Poli M, Sartori M, Girão M "et al". Cistite Recorrente: Tratamento e Prevenção. Assoc. Med. Bras. Ag. Nacion. Saud. Suplemen. 1-12, 2011.

10. Eduardo JCC, Gava IA. O uso de vacinas na proflaxia das infecções do trato urinário. J. Bras. Nefrol., 34(2): 178-183, 2012. 11. Lo DS, Ragazzi SLB, Gilio AE, Martinez MB. Infecção urinária em menores de 15 anos: etiologia e perfil de sensibilidade antimicrobiana em hospital geral de pediatria. Rev. Paul. Ped., 28 (4): 299-303, 2010.

12. Duarte G, Marcolin AC, Quintana SM, Cavalli RC. Infecção urinária na gravidez. Rev Bras Ginecol Obstet. 2008; 30(2):93-100

13. Braios A, Turatti TF, Meredija LCS, Campos TRS, Denadai FHM. Infecções do trato urinário em pacientes não hospitalizados: etiologia e padrão de resistência aos antimicrobianos. J. Bras. Patol. Med. Lab., 45 (6): 449-456, 2009.

14. Rodrigues FJ, Barroso AP. Etiologia e sensibilidade bacteriana em infecções do tracto urinário. Rev. Port. Sau. Pub., 29 (2): 123- 131, 2011.

15. Grillo VTRS, GonsalvezTG, Júnior JC, Paniágua NC, Teles CBG. Incidência bacteriana e perfil de resistência a antimicrobianos em pacientes pediátricos de um hospital público de Rondônia. Ref. Ciênc. Farm. Básica Apl., 34(1): 117-123, 2013.

16. Marques ML, Chade DC, Dourado FL. Aumento da resistência bacteriana no controle de infecção urinária adquirida na comunidade. Sinopse de urologia, 9(5): 121-122, 2005.

17. Guimarães DO, Momesso LS, Pupo MT. Antibióticos: importância terapêutica e perspectivas para descoberta e desenvolvimento de novos agentes. Quim. Nova, Vol. 33, No. 3, 667-679, 2010.

18. Lujána DA, Lujána LM, Mamani E. Resistência a Antibióticos de Cepas Escherichia coli Isoladas de Infecções do Trato Urinário Adquiridas na Comunidade - Cidade de Lima, Peru. Cient. Ciênc. Biol. Saúde, 14 (1): 17-20, 2012.

19. Bail L, Ito CAS, Esmerino LA. Infecção do trato urinário: comparação entre o perfil de susceptibilidade e a terapia empírica com antimicrobianos. RBAC, 38(1): 51-56, 2006.

20. Bertoncheli CM, Hörner R. Uma revisão sobre metalo-ß-lactamases. Brazilian Journal of Pharmaceutical Sciences vol. 44, n. 4, out./dez., 2008.

21. Poletto KQ, Reis C. Suscetibilidade antimicrobiana de uropatógenos em pacientes ambulatoriais na cidade de Goiânia, GO. Rev. Soc. Bras. Med. Trop., Uberaba, v. 38, n. 5, out. 2005. 
22. Carmo MS, Marques AM, Gonçalves LHB, Ferro TAF, Monteiro CA, Bomfim MRQ "et al". Detecção de Betalactamases de Espectro Estendido (ESBL) em Isolados de Escherichia coli Uropatogênicas (UPECs) Oriundos de Pacientes da Comunidade. Rev. Patol. Top., 41 (4): 419-426, 2012.

23. Martini R, Hörner R, Roehrs MCMS, Gindri L, Mielke TP, Rodrigues MA "et al". Caracterização de culturas de urina realizadas no laboratório de análises clínicas do hospital universitário de Santa Maria - Santa Maria, RS, no período de 2007 a 2010. Saúde (Santa Maria), v.37, n.1, p. 5564, 2011.

24. Oplustil CP, Zoccoli CM. Procedimentos Básicos em Microbiologia Clínica. $3^{a}$ Ed. Sarvier, São Paulo, 2010.

25. Clinical and Laboratory Institute - Performance Standards of Antimicrobial Susceptibility Testing. CLSI document M100-S18 (ISBN 1-56238-556-9) Clinical and Laboratory Institute - 940 - West Valley Road - Suite 1400 - Wayne, Pennsylvania 19087 - 1898 USA, 2008.

26. Lo DS, Shieh HH, Ragazzi SLB, Koch VHK, Martinez MB, Gilio AE. Infecção urinária comunitária: etiologia segundo idade e sexo. J. Bras. Nefrol. 2013 June; 35 (2): 93-98.

27. Hoyos Á, Serna L, Ortiz G, Aguirre J. Infección urinaria adquirida en la comunidad en pacientes pediátricos: clínica, factores de riesgo, etiología, resistencia a los antibióticos y respuesta a la terapia empírica. Infect. 2012 June; 16(2): 94-103.

28. Hörner R, Kocourek GED, Domingues VO, Rigatti F, Bertoncheli CM, Paraguinski GL. Comparação de métodos de triagem para detecção de bacteriúria em amostras do bairro Maringá e do Hospital Universitário de Santa Maria. Saúde, Santa Maria, vol 34a, n 1-2: p 16-21, 2008.

29. Molano G, Bayona M, Hinestroza L, Jiménez J, Luna W, Moncada M "et al". Infección por bactérias de vías urinarias em mujeres tratadas com cateter uretral y resistência bacteriana a antibióticos. Revista U.D.C.AActualidad \& Divulgación Científica 15 (1): 27 - 34, 2012.

30. Machado-Alba JE, Murillo-Muñoz MM. Evaluación de sensibilidad antibiótica en urocultivos de pacientes en primer nivel de atención en salud de Pereira. Rev. Salud Pública. 2012 Aug; 14( 4 ): 710-719.

31. Agência Nacional da Vigilância Sanitária - ANVISA. Resolução da Diretoria Colegiada (RDC) $n^{0} 44$, de 26 de outubro de 2010. Disponível em: http://www.portal.anvisa.gov.br. Acessado em junho de 2013.

32. Berquó LS, Barros AJD, Lima RC, Bertoldi AD. Utilização de antimicrobianos em uma população urbana. Rev Saúde Pública 2004; 38(2): 239-46

\section{Ilo Odilon Villa Dias}

Endereço para correspondência - Rua: Israel, nº 73 - D, Bairro: Maria Goretti, CEP: 89801436, Cidade: Chapecó, SC, Brasil.

E-mail: ilodias@unochapeco.edu.br

Lattes: http://lattes.cnpq.br/5395232406294176

Alessandra de Mello Coelho - alem@unochapeco.edu.br Ionara Dorigon - ionara_dorigon@hotmail.com

Enviado em 09 de setembro de 2014. Aceito em 27 de maio de 2015. 
